\title{
Telomeres and telomerase
}

\author{
María A. Blasco, ${ }^{1,3}$ Susan M. Gasser, ${ }^{2}$ and Joachim Lingner ${ }^{2}$ \\ ${ }^{1}$ National Centre of Biotechnology, Madrid E-28049, Spain; ${ }^{2}$ Swiss Institute for Experimental Cancer Research (ISREC), \\ 1066 Epalinges, Switzerland
}

Telomeres are in the spotlight of modern biology. Whether the subject at hand is cancer, gene regulation, organismal aging, or the cloning of mammals, much seems to depend on what happens at the ends of chromosomes. Because glamorous hypotheses often persist without experimental support, it is important to ask ourselves what we really know about telomeres. This was the topic of a recent meeting entitled 'Telomeres and telomerase: cancer, aging, and genetic instability,' held at the Juan March Centre for International Meetings on Biology (Madrid). Leading scientists in the field of telomere biology presented their latest data in an intimate and friendly setting, as summarized below.

\section{Telomere length regulation}

The length of the repetitive DNA that forms the basis of the telomeric cap varies among species, cell types and chromosomes, and may also vary with the age of a given cell. In the yeast Saccharomyces cerevisiae, the average telomere length of $350 \pm 50 \mathrm{bp}$ is maintained by the balance between the opposing activities of telomerase and telomere-shortening processes, such as the mechanisms of lagging-strand synthesis and, possibly, an exonuclease activity (Wellinger et al. 1996). Work from the laboratories of David Shore (University of Geneva, Switzerland) and Eric Gilson (Ecole Normale Supérieure, France) has shown that the telomerase-dependent extension of the TG-rich strand in yeast is regulated by a negative feedback mechanism that monitors the length of the doublestranded TG-rich repeat (Marcand et al. 1997). More precisely, they have demonstrated that the complement of Raplp molecules bound to a specific telomere end acts in cis to limit telomerase-mediated extension.

The Gilson laboratory has made several new observations on the kinetics of elongation by producing sudden changes in the length of a given chromosomal end and monitoring the rate of elongation or degradation as equilibrium is restored (Marcand et al. 1999). First, it was shown that following the FLP recombinase-mediated excision of a subtelomeric TG-stretch, the terminal TG repeat lengthens to restore its original length by a RAD52-independent and telomerase-dependent mecha-

${ }^{3}$ Corresponding author.

E-MAIL mblasco@cnb.uam.es; FAX 34-91-372-0493. nism (Marcand et al. 1999). The action of telomerase requires passage into $S$ phase, and appears to be coupled to chromosomal replication. Detailed kinetic studies show that the rate of elongation, which is at most $~ 15 \mathrm{bp}$ per generation, decreases progressively with the increasing length of the TG repeat, whereas the rate of degradation is constant. Together this suggests a model by which telomerase is gradually inhibited as telomere length extends, most probably due to the Rap1p-bound proteins, Rif1p and Rif2p (Wotton and Shore 1997).

The laboratories of Virginia Zakian (Princeton University, USA) and David Shore have shown that Rif1p is associated with the yeast telomere, where it competes with the silent information regulators, Sir3p and Sir4p, for the carboxy-terminal domain of the TG-repeat binding protein, Raplp (Fig. 1; Wotton and Shore 1997; Bourns et al. 1998). Elimination of the Rif proteins results in greatly extended telomeres, yet Shore reported that this can be compensated by coupling these mutations with loss of another telomere associated factor, yKu. In addition to affecting telomere length, the yKu70/80 dimer itself helps recruit Sir proteins to subtelomeric sites, promoting the repression of nearby reporter genes (Mishra and Shore 1999; Martin et al. 1999). Intriguingly, Shore now finds that $\mathrm{yKu} 70$ binds the Rif1 protein as well as Sir4. Consistent with the model that Rif 1 competes for the binding of Sir proteins to the Rap1 carboxyl terminus, the loss of telomeric position effect that occurs in a yKu mutant can be restored by deletion of Rif1 (Mishra and Shore 1999). With respect to length maintenance, it is still unclear which proteins communicate between these telomeric factors (Rif1, Rif2, Rap1, $\mathrm{yKu}$, and Sir proteins) and the telomerase complex itself. It is predicted that such proteins might limit telomerase activity in a dose-dependent manner. Alternatively, the folding of telomeric DNA into a higher-order structure may regulate the accessibility to telomerase or to singlestrand telomere binding proteins that are required for in vivo telomerase action (see below).

Telomere length in mammals may also be influenced by the telomeric chromatin structure. Jordi Surrallés (Universitat Autònoma de Barcelona, Spain) showed that telomeres of the inactive $\mathrm{X}$ chromosome are consistently shorter than those of all the other chromosomes, including the active $\mathrm{X}$. The inactive $\mathrm{X}$ chromosome is heterochromatic, hypermethylated, and contains underacetylated histones, suggesting a link between chromatin 
Figure 1. Model of a yeast telomere. The Sir2/ $3 / 4$ (green ovals) and the Rif1/2 (red ovals) complexes compete for binding to the Rap1 (yellow) carboxyl terminus and can also both interact with the Ku70/80 dimer (lavender). $\mathrm{Ku} 70 / 80$ may also bind to telomeric DNA directly. Cdc13p (gray) and Est1 (purple) may recruit telomerase to the telomeric $3^{\prime}$ end in $S$ phase.

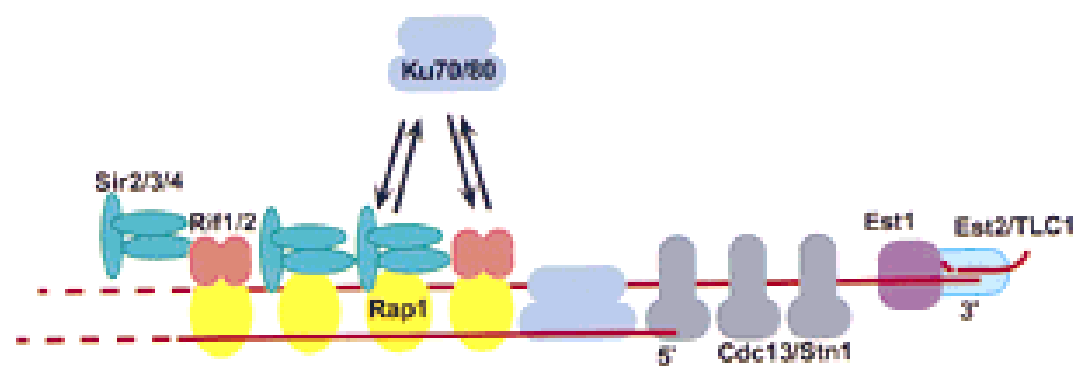

structure and the mechanism of telomere length maintenance in mammals as well.

\section{Distinguishing telomeres from DNA strand breaks}

The yKu heterodimer is one of the more promiscuous members of the telomere complex, for not only is it bound near the chromosomal end, but it spreads along subtelomeric heterochromatin and is recruited to sites of double-strand breaks, where it promotes nonhomologous end-joining reactions. Recent studies reported by Susan Gasser (Swiss Institute for Experimental Cancer Research, Switzerland) have monitored how telomeres respond to the induction of DNA strand breaks in vivo (Martin et al. 1999). Surprisingly, a single double-strand DNA break is sufficient to elicit a Rad9/Mec1-dependent checkpoint response that not only arrests cell cycle progression, but provokes a major relocalization of telomere-bound factors to this site of damage (Martin et al. 1999; Mills et al. 1999). The yeast Ku complex, and the subtelomeric heterochromatin proteins Sir2, 3, and 4, and Rap1 itself, were all shown to respond to the Mec1 signaling pathway by being displaced from the telomere and recruited to the site of repair. It seems possible that these ATM-like kinase-mediated changes not only promote double-strand break repair, but also may help protect telomeres from the ligase IV-mediated religation events that occur at properly processed double-strand breaks. Whether Sir proteins play a role in the repair of DNA damage or in the stabilization of unrepaired ends remains a topic of intense research.

Interestingly, results presented at this meeting suggest that the protection of telomeres from end-to-end fusion not only depends on telomere binding proteins, but may also involve an unusual DNA structure that was seen to form at mammalian telomeres. Titia de Lange (Rockefeller University, USA) and Jack Griffiths (University of North Carolina at Chapel Hill, USA) have shown by cross-linking and electron microscopy that the extreme ends of human chromosomes are tucked into the doublestrand repeat forming a loop, which may serve to protect the sensitive 3' overhang of telomeric DNA /Griffith et al. 1999). De Lange presented a model in which the local displacement of the TG-rich strand internally is stabilized by the telomeric protein TRF2, whereas the rest of the normal duplex telomeric DNA is also bound by the closely related protein TRF1 (Fig. 2). This TG-strand invasion model not only protects the chromosomal end from ligation complexes and end-to-end fusions but could serve as an alternative means to elongate telomeric repeat DNA. Although such events have not yet been documented, it is conceivable that the invasion of the double-strand repeat by the single-stranded tail provides a 3' $\mathrm{OH}$ for elongation of the tail by a leading-strand DNA polymerase, obviating the need for telomerase activity. Whether this occurs under normal growth conditions, in telomerase-deficient cells, or not at all, remains to be seen. In any case, the fact that telomere length maintenance is absolutely critical to cell survival makes it likely that nature has invented multiple mechanisms to maintain the ends of chromsomes.

Another remarkable mechanism of chromosome end maintenance is found in Drosophila, where retrotransposons target and maintain the chromosomal end. Although Drosophila telomeres appear to be structurally very different from most other eukaryotic telomeres, they must share some telomere functions, most notably the protection from end-to-end fusion. Maurizio Gatti (Universitá di Roma, Italy), reported the isolation of a large collection of Drosophila mutants that promote

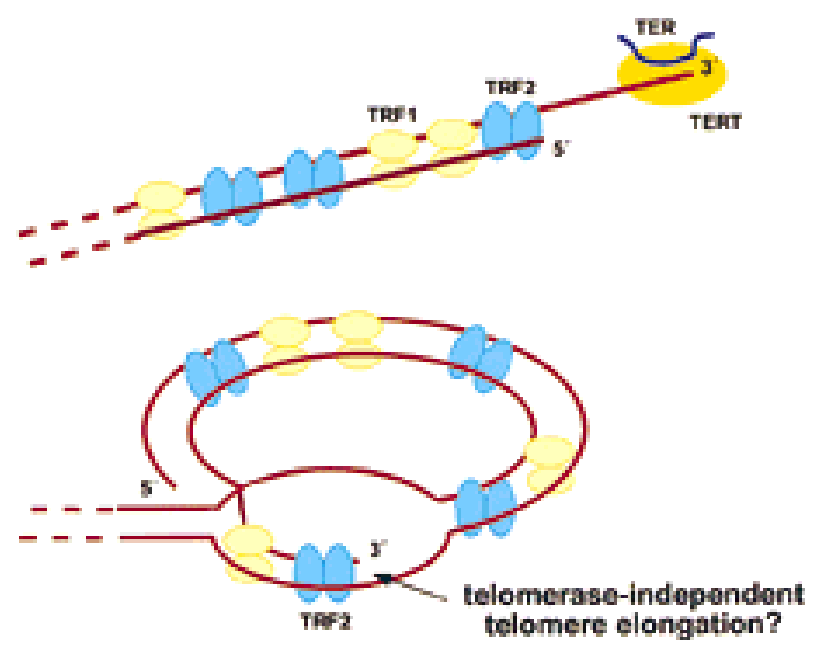

Figure 2. Model of mammalian telomeres. Two possible conformations of mammalian telomeres. The linear conformation (top) leaves an exposed telomere end accesible to telomerase, exonucleases, DNA repair enzymes, etc. The looped telomere (bottom) masks telomere termini and provides a way to elongate telomeres by conventional DNA polymerases, in a telomerase-independent reaction. The telomere binding proteins TRF1 and TRF2 are shown in yellow and blue, respectively. 
telomere fusions, resulting in polycentric linear and ring chromosomes. Some of the observed fusions are very tight and are maintained during anaphase, whereas others can be resolved. Surprisingly, two of the genes identified to date encode enzymes of the ubiquitin pathway (Cenci et al. 1997). In view of the conserved nature of ubiquitin, it was proposed that a similar family of enzymes will be important for proper telomeric function in yeast and/or mammals.

\section{Aging, cancer, and mammalian telomeres}

Although the above studies attempt to unravel the molecular mechanisms underlying normal telomere regulation, others have examined the dynamics of telomere length in cellular and organismal aging, and in cancerogenesis. Peter Lansdorp (Terry Fox Laboratory, Canada) reported that the rate of telomere shortening with increasing population doublings in cultured human fibroblasts varies between individual telomeres (ranging from 150 to $50 \mathrm{bp} /$ cell division). Interestingly, those telomeres that are shorter initially, such as telomere $17 \mathrm{p}$ in humans (Martens et al. 1998), are not necessarily the first ones to be lost. Indeed, the shortening of telomeres $22 p, 1 p$, and $5 p$, but not that of $17 p$, shows a statistically significant correlation with the induction of cellular senescence. These determinations are essential for understanding the role of telomeres in cancer and aging. It is not yet clear whether chromosomal instability is triggered by any telomere that reaches a critical length, or whether specific ends play specific roles in these events.

Calvin Harley (Geron Corp., USA) and Jerry Shay (University of Texas Southwestern Medical Center, USA) described telomere dynamics in human cells that had been immortalized by a forced activation of the telomerase RNP. The reactivation of telomerase in normal adult cells has been envisioned as a way of extending their life spans for therapeutic purposes, notably for diseases associated with aging (Bodnar et al. 1998). Harley proposed that reactivation of telomerase will provide a means to 'refresh' telomeres in adult somatic cells, prior to mammalian cloning and in vitro tissue production. In this regard, both Harley and Shay mentioned that different cell types stabilized telomeres at different lengths upon the introduction of telomerase. Interestingly, Shay showed that the introduction of telomerase into fibroblast cells from patients with inherited syndromes such as Xeroderma Pigmentosum (XP), Bloom's syndrome (BS), Robert's syndrome, Werner syndrome and Hutchinson-Gillford progeria, immortalized the cells but did not necessarily ablate their phenotypic lesion. Thus, 'telomerized' XP cells were still UV sensitive and cells derived from BS patients still had increased sister chromatid exchanges. This suggests that introducing telomerase into cells from patients with various genetic disorders may separate the underlying genetic lesions from those that may be produced by progressive telomere shortening due to normal fibroblast cell culture.

Studies on telomere shortening in mammals also raise the question of how telomerase is regulated during nor- mal development, and what kind of genetic changes lead to its activation in tumors. The understanding of telomerase regulation is still very limited, but some regulators are being identified. Silvia Bacchetti (McMaster University, Canada) provided evidence that estrogen can stimulate hTERT (human telomerase reverse transcriptase) expression in normal ovary epithelial cells by activating the hTERT promoter. Robert Newbold (Uxbridge, UK) reported the mapping of a region on human chromosome 3 , that when transduced into the breast cancer cell line $21 \mathrm{NT}$ represses telomerase and induces senescence. This study therefore argues for the existence of repressors in normal somatic cells that down-regulate telomerase.

\section{The mouse telomerase knockout model}

It is clear that mastering telomere biology will have a significant impact on human health care. First, telomerase is activated in $>90 \%$ of all types of tumors and has been proposed to be a potential target of chemotherapy. Second, genetic diseases that provoke premature aging show an accelerated rate of telomere shortening. Related to the dual problem of aging and cancer, Ronald DePinho (Dana Farber Cancer Institute, USA) described mice defective for both telomerase, $\mathrm{mTER}^{-1-}$ (mice deficient for the mouse telomerase RNA; Blasco et al. 1997) and tumor suppressor protein $\mathrm{p} 16 / \mathrm{p} 19^{\mathrm{ARF}}$ or $\mathrm{p} 53$, respectively. Double knockout mice $\mathrm{mTER}^{-/-} /\left(\mathrm{p} 16 / \mathrm{p} 19^{\mathrm{ARF}}\right)^{-/-}$from late generation that had short telomeres showed a $50 \%$ reduction in the number of tumors that developed as compared with (p16/p19 $\left.{ }^{\mathrm{ARF}}\right)^{-/-}$mice (Greenberg et al. 1999|. This suggests that even though short telomeres and the absence of telomerase do not prevent tumorigenesis in the mouse (see also Blasco et al. 1997; Rudolph et al. 1999), the presence of telomerase seems to promote tumor progression, presumably by preventing further telomere shortening. This supports the idea that anti-telomerase chemotherapy may help to impede tumor growth. Data from the double knockout $\mathrm{mTER}^{-/} / \mathrm{p} 53^{-/-}$, revealed that the absence of the p53 protein delays the appearance of phenotypes associated with telomerase deficiency, presumably due to an initial decrease in apoptosis mediated by p53 (Chin et al. 1999). Indeed, Titia de Lange had shown previously that loss of telomeric function in TRF2 mutants induces apoptosis mediated by p53 and ATM proteins (Karlseder et al. 1999).

Exciting new data were also presented regarding the importance of telomerase and telomeres for aging. Ronald DePinho showed that the telomerase knockout mice, $\mathrm{mTER}^{-/}$, show defects associated with aging after the mice reach an old age (>18 months) (Rudolph et al. 1999). María Blasco (National Centre of Biotechnology, Spain) further reported that the telomerase deficiency has an even stronger impact on life span if the mTER-null mutation is in a genetic background with shorter telomeres (Herrera et al. 1999). From Blasco's and DePinho's work it seems clear that the consequences of telomere shortening occur in tissues that have high proliferation rates, such as organs of the hematopoietic system and the gut. One would predict that telomere shortening with age in 
humans could trigger similar pathological states. In particular, Blasco showed that the immune system of lategeneration telomerase-deficient mice is greatly affected. These mice show splenic atrophy, abnormal hematology, an impaired reaction of $\mathrm{B}$ and $\mathrm{T}$ cells to mitogen stimulation as well as a defective germinal center reaction following antigen immunization, all landmarks of immunosenescence.

To explain tumor growth in $\mathrm{mTER}^{-/-}$mice that at the same time show severe proliferative dissorders we need to invoke the activation of telomerase-independent telomere elongation in some cells. In this regard, Blasco presented data showing that telomerase-independent elongation mechanisms could be operating in the hematopoietic organs of late generation telomerase-deficient mice. In particular, telomeres are elongated in late generation mTER $^{-/-}$mice during the high proliferation that B cells undergo at the splenic germinal centers during the immune response. The study of mice that are deficient both for telomerase activity and DNA repair or recombination proteins could help to identify the nature of proteins involved in telomerase-independent telomere maintenance.

In this regard, Roger Reddel (Children's Medical Research Institute, Australia) presented an update on human cells that maintain telomeres without telomerase (ALT cells) (Bryan et al. 1995, 1997). Experimental evidence from yeast suggests that the ALT mechanism in human cells could be recombinational, so that telomeres are extended using existing telomeres as template. Alternatively, as mentioned above, the existence of $\mathrm{T}$ loops raises the possibility that a telomere might be able to use itself rather than another telomere as template. Reddel reported that $5 \%-10 \%$ of ALT interphase nuclei exhibit an apparently unique form of promyelocytic leukemia (PML) body. (PML bodies are nuclear structures and are so-named because they contain PML protein, which derives its name from the observation that in PML this protein is often fused to another protein due to a chromosomal translocation). In ALT cells the PML bodies contain telomeric DNA, the telomeric proteins TRF1 and TRF2, as well as the recombination proteins Rad51 and Rad52. Whether this type of PML body indicates the occurrence of telomeric recombination mediated by $\mathrm{T}$ loops remains to be determined.

\section{The telomerase complex}

It has been known for over a decade that telomerase functions as a reverse transcriptase (RT) (Greider and Blackburn 1989; Yu et al. 1990). A tightly associated RNA subunit (TER) provides the template for telomeric repeat synthesis, and the active site of the protein subunit shares sequence features with RTs of retroviruses and retroements (Lingner et al. 1997b; Nakamura and Cech 1998). Although the catalytic subunit of telomerase, TERT shares the hallmarks of other RTs, it forms a novel subgroup in this protein family and has distinct sequence features. From the biochemical point of view, TERT has some properties that distinguish it from clas- sical RTs. Using the $3^{\prime} \mathrm{OH}$ at the DNA terminus as a primer, telomerase copies repeatedly only a very restricted region of the telomerase RNA component, the so-called template region. This repeated reverse transcription of the template region can occur in a more or less processive manner in vitro, depending on the source of the enzyme and the reaction conditions employed (Morin 1989; Greider 1991; Lee and Blackburn 1993; Prowse et al. 1993; Hammond and Cech 1997).

To reveal how the primary sequence features that are unique to TERT relate to its function, Tracy Bryan (University of Colorado-Boulder, USA) dissected the differences between TERTs and classical RTs using a sitedirected mutagenesis approach. When a TERT-conserved leucine residue was changed to the retroviral RT-conserved tyrosine residue near the active site aspartates, the processivity of reticulocyte lysate-translated Tetrahymena TERT was increased and thus resembled more a classical RT in that respect. Using hTERT and the reticulocyte system (Weinrich et al. 1997), Lea Harrington (Amgen Institute/University of Toronto, Canada) determined to what extent domains outside the RT domain of TERT are required for reconstitution and telomerase activity. In this system, the RT domain was not sufficient to reconstitute activity, indicating that the TERT regions outside the RT domain are essential for activity.

Are TERT and telomerase RNA sufficient for reconstitution of activity? Interestingly, Shay reported the requirement of two chaperone proteins that are present in the reticulocyte lysate and that are required to reconstitute activity from hTERT and hTER in this system (Holt et al. 1999). Kathleen Collins (University of CaliforniaBerkeley, USA) also found that a reticulocyte lysate component is required to reconstitute telomerase activity from in vitro transcribed Tetrahymena TERT and telomerase RNA (Licht and Collins 1999).

The telomerase RNA moiety of ciliates has a length of 160-200 nucleotides and a phylogenetically conserved secondary structure (Romero and Blackburn 1991; Lingner et al. 1994; McCormick-Graham and Romero 1995). Recently, a pseudoknot structure conserved in the ciliate telomerase RNA was found to be necessary for in vivo assembly with TERT, thus being the first structural element of telomerase RNA with a clearly assigned function (Gilley and Blackburn 1999). In mammals and yeast, the telomerase RNAs are much longer-450 and 1300 nucleotides, respectively (Singer and Gottschling 1994; Blasco et al. 1995; Feng et al. 1995) -and it is unclear which structural elements may be universally conserved. As a step toward analyzing the human telomerase RNA hTER, both Shay and Harrington reported a deletion analysis of this molecule. Functionality was tested in vitro, in the reticulocyte transcription/translation system in which hTERT is expressed and telomerase activity is reconstituted with hTER (Weinrich et al. 1997). Regions upstream of the hTER template were found to be mostly dispensable for reconstituting activity. However, downstream of the template the RNA contains domains critical for activity and/or assembly. Shay also reported that separate hTER fragments $1+33$ to +147 
and +164 to +325 ) that are not functional for reconstitution by themselves, function to reconstitute activity when combined in trans (Tesmer et al. 1999).

New data were also presented regarding the mutation of protein telomerase components in mice. Harrington presented the characterization of the knockouts of mTERT, the catalytic subunit of mouse telomerase (Greenberg et al. 1998; Martín-Rivera et al. 1998), and TEP1, a telomerase-associated protein that binds the telomerase RNA (Harrington et al. 1997a; Nakayama et al. 1997). The mTERT $^{-/-}$embryonic stem cells lack telomerase activity and show telomere shortening with increasing passage in culture, as expected from a knockout in an essential component of telomerase. Surprisingly, TEP1 knockouts show normal levels of telomerase activity and do not show telomeric shortening, suggesting that TEP1 is not required for telomerase activity nor telomere maintenance in vivo. Interestingly, TEP1 is a component of the vault complex (V. Kickhoefer and L. Rome pers. comm.), a large 13-MD ribonucleoprotein particle of unknown function (Kong et al. 1999). The significance of this finding for telomerase and telomere biology remains to be seen.

Telomere maintenance in $S$. cerevisiae requires not only the telomerase catalytic subunit Est2p and the telomerase RNA TLC1, but also several other telomerase-associated proteins. Vicki Lundblad (Baylor College of Medicine, USA) reported further analysis of the EST (ever shorter telomere) gene products (Lundblad and Szostak 1989; Lendvay et al. 1996). Est1p and Est3p are known to be required for telomere maintenance in vivo but not for telomerase activity in vitro (Cohn and Blackburn 1995; Lingner et al. 1997a). Est1p, Est2p, and Est3p are associated with the telomerase RNA moiety TLC1 as shown by immunoprecipitation experiments (Lin and Zakian 1995; Steiner et al. 1996; Lingner et al. 1997a). Apart from Est1p being a component of the telomerase complex, it is also a prime candidate for mediating its interaction with the very $3^{\prime}$ tip of the chromosome (see Fig. 1). Est1p has single-stranded telomeric DNA-binding activity and requires a single-stranded 3 ' end for binding (Virta-Pearlman et al. 1996). Another putative singlestranded telomere binding protein, Cdc13p, may bind to the telomeric $3^{\prime}$ overhang more internally (Lin and Zakian 1996; Nugent et al. 1996). The concentration of telomerase in vivo and its affinity for telomeric DNA may not be sufficient to allow efficient telomere elongation in the absence of Est1p or Cdc13p. On the other hand, if telomere $\mathrm{T}$ loops occur in yeast, Cdc13p and Est1p may also have a role in preventing the formation of such a structure during telomere elongation in S phase, thus maintaining telomeric DNA in a telomerase competent state. To understand telomere length regulation, it will be important to elucidate when and how the binding of the single-stranded telomere binding proteins and/ or telomerase is regulated.

\section{Passage through the nucleolus?}

The identification of a structural element in a nonciliate telomerase RNA was reported by Kathleen Collins (Mitchell et al. 1999). An H/ACA type motif is present at the 3' end of human telomerase RNA. This element is typically found in small nucleolar RNAs (snoRNAs) that assemble into small ribonucleolar protein (snRNP) particles that guide the pseudouridylation of rRNA precursors (Weinstein and Steitz 1999). The function of the $\mathrm{H} / \mathrm{ACA}$ motif in human telomerase RNA is unclear. It would be unexpected but possible that the H/ACA motif of the telomerase RNA would guide pseudouridylation of itself or another RNA, as do its related snoRNPs. On the other hand, the H/ACA motif may have been borrowed by telomerase for biogenesis or stability purposes. It was noted by Joachim Lingner (Swiss Institute for Experimental Cancer Research, Switzerland), however, that hTERT is not predominantly nucleolar but is found in numerous nucleoplasmic foci (Harrington et al. 1997b; Martín-Rivera et al. 1998) when analyzed in tumor-derived telomerase-positive cells or in cells in which hTERT was expressed ectopically. The TERTcontaining foci are of unknown identity, yet do not colocalize with the splicing factor SC35. A transient association with the nucleolus during human telomerase maturation, however, seems plausible given the presence of the H/ACA motif. Similarly, snoRNPs themselves do not have a constitutive nucleolar localization but are thought to pass through the nucleolus during maturation (Pederson 1998).

The subnuclear localization of the yeast TERT Est $2 p$ was also examined, using the direct epifluorescence of a functional Est2p-GFP fusion (Joachim Lingner). Rather than colocalizing with the discrete perinuclear foci of yeast telomeres, the fusion protein was found weakly distributed through the nucleoplasm and enriched in the nucleolus. Because the yeast telomerase RNA TLC1 has no apparent H/ACA motif, Est2p appears to associate with the nucleolus by other means. It has not been excluded, however, that TLC1 also passes through the nucleolus, perhaps acquiring modifications that allow efficient assembly with the protein moiety.

From the 3 days in Madrid and our report here it should become clearer than ever before that genetic, cytological, and biochemical studies in yeast and mammals alike provide a powerful and fruitful means to unravel how the eukaryotic cell produces and maintains its chromosomal ends. The ambitious goals of workers in this young, but very dynamic field, promise new and exciting findings in the near future.

\section{Acknowledgments}

We thank all the speakers at the meeting for sharing their data and the reviewers for their helpful comments.

\section{References}

Blasco, M.A., W. Funk, B. Villeponteau, and C.W. Greider. 1995. Functional characterization and developmental regulation of mouse telomerase RNA. Science 269: 1267-1270.

Blasco, M.A., H.-W. Lee, P. Hande, E. Samper, P. Lansdorp, R. 
DePinho, and C.W. Greider. 1997. Telomere shortening and tumor formation by mouse cells lacking telomerase RNA. Cell 91: 25-34.

Bodnar, A.G., M. Ouellette, M. Frolkis, S.E. Holt, C-P. Chiu, G.B. Morin, C.B. Harley, J.W. Shay, S. Lichtsteiner, and W.E. Wright. 1998. Extension of life-span by introduction of telomerase into normal human cells. Science 279: 349-352.

Bourns, B.D., M.K. Alexander, A.M. Smith, and V.A. Zakian. 1998. Sir proteins, Rif proteins, and Cdc13p bind Saccharromyces telomeres in vivo. Mol. Cell. Biol. 18: 5600-5608.

Bryan, T.M., A. Englezou, J. Gupta, S. Bacchetti, and R.R. Reddel. 1995. Telomere elongation in immortal human cells without detectable telomerase activity. EMBO J. 14: 42404248.

Bryan, T.M., L. Marusic, S. Bacchetti, M. Namba, and R.R. Reddel. 1997. The telomere lengthening mechanism in telomerase-negative immortal human cells does not involve the telomerase RNA subunit. Hum. Mol. Genet. 6: 921-926.

Cenci, G., R.B. Rawson, G. Belloni, D.H. Castrillon, M. Tudor, R. Petrucci, M.L. Goldberg, S.A. Wasserman, and M. Gatti. 1997. UbcD1, a Drosophila ubiquitin-conjugating enzyme required for proper telomere behavior. Genes \& Dev. 11: $863-875$

Chin, L., S.E. Artandi, Q. Shen, A. Tam, S-L. Lee, J. Gottlieb, C. Greider, and R. DePinho. 1999. p53 deficiency rescues the adverse effects of telomere loss and cooperates with telomere dysfunction to accelerate carcinogenesis. Cell 97: 527538

Cohn, M. and E.H. Blackburn. 1995. Telomerase in yeast. Science 269: 396-400.

Feng, J., W.D. Funk, S.S. Wang, S.L. Weinrich, A.A. Avilion, C.P. Chiu, R.R. Adams, E. Chang, R.C. Allsopp, J. Yu, et al. 1995. The RNA component of human telomerase. Science 269: 1236-1241.

Gilley, D. and E.H. Blackburn. 1999. The telomerase RNA pseudoknot is critical for the stable assembly of a catalytically active ribonucleoprotein. Proc. Nat1. Acad. Sci. 96: 66216625.

Greenberg, R.A., R.C. Allsopp, L. Chin, G. Morin, and R. DePinho. 1998. Expression of mouse telomerase reverse transcriptase during development, differentiation and proliferation. Oncogene 16: 1723-1730.

Greenberg, R.A., L. Chin, A. Femino, K-H. Lee, G.J. Gottlieb, R. Singer, C.W Greider, and R. DePinho. 1999. Short dysfunctional telomeres impair tumorogenesis in the INK4a cancer prone mouse. Cell 97: 515-525

Greider, C.W. 1991. Telomerase is processive. Mol. Cell. Biol. 11: 4572-4580.

Greider, C.W. and E.H. Blackburn. 1989. A telomeric sequence in the RNA of Tetrahymena telomerase required for telomere repeat synthesis. Nature 337: 331-337.

Griffith, J.D., L. Comeau, S. Rosenfield, R.M. Stansel, A. Bianchi, H. Moss, and T. de Lange. 1999. Mammalian telomeres end in a large duplex loop. Cell 97: 503-514

Hammond, P.W. and T.R. Cech. 1997. dGTP-dependent processivity and possible template switching of euplotes telomerase. Nucleic Acids Res. 25: 3698-3704.

Harrington, L., T. McPhail, V. Mar, W. Zhou, R. Oulton, M.B. Bass, I. Arruda, and M.O. Robinson. 1997a. A mammalian telomerase-associated protein. Science 275: 973-977.

Harrington, L., W. Zhou, T. McPhail, R. Oulton, D.S. Yeung, V. Mar, M.B. Bass, and M.O. Robinson. 1997b. Human telomerase contains evolutionarily conserved catalytic and structural subunits. Genes \& Dev. 11: 3109-3115.

Herrera, E., E. Samper, J. Martín-Caballero, J.M. Flores, H-W. Lee, and M.A. Blasco. 1999. Disease states associated to telomerase deficiency appear earlier in mice with short telomeres. EMBO J. 18: 2950-2960

Holt, S.E., D.L. Aisner, J. Baur, V.M. Tesmer, M. Dy, M. Ouellette, J.B. Trager, G.B. Morin, D.O. Toft, J.W. Shay, W.E. Wright, and M.A. White. 1999. Functional requirement of p23 and Hsp90 in telomerase complexes. Genes \& Dev. 13: $817-826$.

Karleseder, J., D. Broccoli, Y. Dai, S. Hardy, and T. de Lange 1999. p53 and ATM dependent apoptosis induced by telomeres lacking TRF2. Science 283: 1321-1325

Kong, L.B., A.C. Siva, L.H. Rome, and P.L. Stewart. 1999. Structure of the vault, a ubiquitous cellular component. Structure 7: 371-379.

Lee, M.S. and E.H. Blackburn. 1993. Sequence-specific DNA primer effects on telomerase polymerization activity. Mol. Cell. Biol. 13: 6586-6599.

Lendvay, T.S., D.K. Morris, J. Sah, B. Balasubramanian, and V. Lundblad. 1996. Senescence mutants of Saccharomyces cerevisiae with a defect in telomere replication identify three additional EST genes. Genetics 144: 1399-1412.

Licht, J.D. and K. Collins. 1999. Telomerase RNA function in recombinant Tetrahymena telomerase. Genes \& Dev. 13: $1116-1125$.

Lin, J.J. and V.A. Zakian. 1995. An in vitro assay for Saccharomyces telomerase requires EST1. Cell 81: 1127-1135.

- 1996. The Saccharomyces CDC13 protein is a singlestrand $\mathrm{TG}_{1-3}$ telomeric DNA-binding protein in vitro that affects telomere behavior in vivo. Proc. Natl. Acad. Sci. 93: $13760-13765$.

Lingner, J., L.L. Hendrick, and T.R. Cech. 1994. Telomerase RNAs of different ciliates have a common secondary structure and a permuted template. Genes \& Dev. 8: 1984-1998.

Lingner, J., T.R. Cech, T.R. Hughes, and V. Lundblad. 1997a. Three Ever Shorter Telomere (EST) genes are dispensable for in vitro yeast telomerase activity. Proc. Natl. Acad. Sci. 94: 11190-11195.

Lingner, J., T.R. Hughes, A. Shevchenko, M. Mann, V. Lundblad, and T.R. Cech. 1997b. Reverse transcriptase motifs in the catalytic subunit of telomerase. Science 276: 561-567.

Lundblad, V. and J.W. Szostak. 1989. A mutant with a defect in telomere elongation leads to senescence in yeast. Cell 57: 633-643.

Marcand, S., E. Gilson, and D. Shore. 1997. A protein-counting mechanism for telomere length regulation in yeast. Science 275: 986-990.

Marcand, S., V. Brevet, and E. Gilson. 1999. Progressive cisinhibition of telomerase upon telomere elongation. EMBO $\mathrm{T}$. 18: 3509-3519.

Martens, U.M., J.M. Zijlmans, S.S. Poon, W. Dragowska, J. Yui, E.A. Chavez, R.K. Ward, and P.M. Lansdorp. 1998. Short telomeres on human chromosome 17p. Nat. Genet. 18: 7680.

Martin, S.G., T. Laroche, N. Suka, M. Grunstein, and S.M. Gasser. 1999. Relocalization of telomeric Ku and SIR proteins in response to DNA strand breaks in yeast. Cell 97: 621-633.

Martín-Rivera, L., E. Herrera, J.P. Albar, and M.A. Blasco. 1998 Expression of mouse telomerase catalytic subunit in embryos and adult tissues. Proc. Natl. Acad. Sci. 95: 1047110476.

McCormick-Graham, M. and D.P. Romero. 1995. Ciliate telomerase RNA structural features. Nucleic Acids Res. 23: 10911097.

Mills, K.D., D.A. Sinclair, and L. Guarente. 1999. MEC1-dependent redistribution of the Sir3 silencing protein from telomeres to DNA double-strand breaks. Cell 97: 609-620

Mishra, K. and D. Shore. 1999. Yeast Ku proteins play a direct 
role in telomeric silencing and counteract inhibition by Riflp. Curr Biol. (in press).

Mitchell, J.R., J. Cheng, and K. Collins. 1999. A box H/ACA small nucleolar RNA-like domain at the human telomerase RNA 3' end. Mol. Cell. Biol. 19: 567-576.

Morin, G.B. 1989. The human telomere terminal transferase enzyme is a ribonucleoprotein that synthesizes TTAGGG repeats. Cell 59: 521-529.

Nakamura, T.M. and T.R. Cech. 1998. Reversing time-Origin of telomerase. Cell 92: 587-590.

Nakayama, J., M. Saito, H. Nakamura, A. Matsuura, and F. Ishikawa. 1997. TLP1: A gene encoding a protein component of mammalian telomerase is a novel member of WD repeats family. Cell 88: 875-884.

Nugent, C.I., T.R. Hughes, N.F. Lue, and V. Lundblad. 1996. Cdc13p: a single-strand telomeric DNA-binding protein with a dual role in yeast telomere maintenance. Science 274: 249-252.

Pederson, T. 1998. The plurifunctional nucleolus. Nucleic Acids Res. 26: 3871-3876.

Prowse, K.R., A.A. Avilion, and C.W. Greider. 1993. Identification of a nonprocessive telomerase activity from mouse cells. Proc. Natl. Acad. Sci. 90: 1493-1497.

Romero, D.P. and E.H. Blackburn. 1991. A conserved secondary structure for telomerase RNA. Cell 67: 343-353.

Rudolph, K.L., S. Chang, H-W. Lee, M. Blasco, G. Gottlieb, C.W. Greider, and R.A. DePinho. 1999. Longevity, stress response, and cancer in aging telomerase deficient mice. Cell 96: 701712 .

Singer, M.S. and D.E. Gottschling. 1994. TLC1: template RNA component of Saccharomyces cerevisiae telomerase. Science 266: 404-409.

Steiner, B.R., K. Hidaka, and B. Futcher. 1996. Association of the Est1 protein with telomerase activity in yeast. Proc. Natl. Acad. Sci. 93: 2817-2821.

Tesmer, V.M., L.P. Ford, S.E. Holt, B.C. Frank, X. Yi, D.L. Aisner, M. Ouellette, J.W. Shay, and W.E. Wright. 1999. Two interactive fragments of the integral RNA cooperate to assemble active telomerase with the human protein catalytic subunit in vitro. Mol. Cell. Biol. 19: 6207-6216.

Virta-Pearlman, V., D.K. Morris, and V. Lundblad. 1996. Est1 has the properties of a single-stranded telomere end-binding protein. Genes \& Dev. 10: 3094-3104.

Weinrich, S.L., R. Pruzan, L. Ma, M. Ouellette, V.M. Tesmer, S.E. Holt, A.G. Bodnar, S. Lichtsteiner, N.W. Kim, J.B. Trager, R.D. Taylor, R. Carlos, W.H. Andrews, W.E. Wright, J.W. Shay, C.B. Harley, and G.B. Morin. 1997. Reconstitution of human telomerase with the template RNA component hTR and the catalytic protein subunit hTRT. Nat. Genet. 17: 498-502.

Weinstein, L.B. and J.A. Steitz. 1999. Guided tours: from precursor snoRNA to functional snoRNP. Curr. Opin. Cell Biol. 11: 378-384.

Wellinger, R.J., K. Ethier, P. Labrecque, and V.A. Zakian. 1996. Evidence for a new step in telomere maintenance. Cell 85: 423-433.

Wotton, D. and D. Shore. 1997. Novel Raplp-interacting factor, Rif2p, cooperates with Rif1p to regulate telomere length in Saccharomyces cerevisiae. Genes \& Dev. 11: 748-760.

Yu, G.L., J.D. Bradley, L.D. Attardi, and E.H. Blackburn. 1990. In vivo alteration of telomere sequences and senescence caused by mutated Tetrahymena telomerase RNAs. Nature 344: 126-132. 


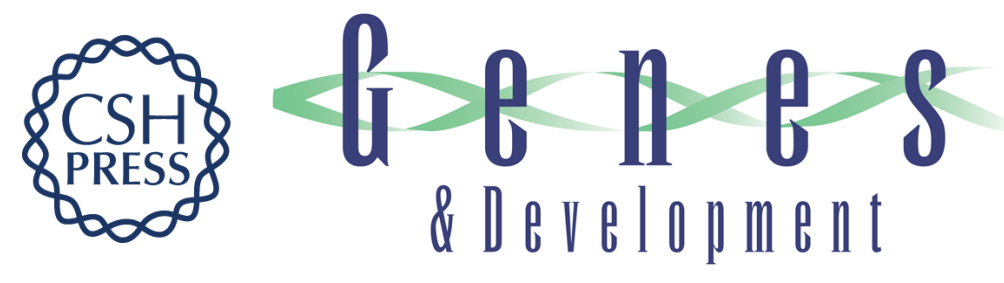

\section{Telomeres and telomerase}

María A. Blasco, Susan M. Gasser and Joachim Lingner

Genes Dev. 1999, 13:

References This article cites 57 articles, 31 of which can be accessed free at: http://genesdev.cshlp.org/content/13/18/2353.full.html\#ref-list-1

License

Email Alerting

Receive free email alerts when new articles cite this article - sign up in the box at the top Service right corner of the article or click here.

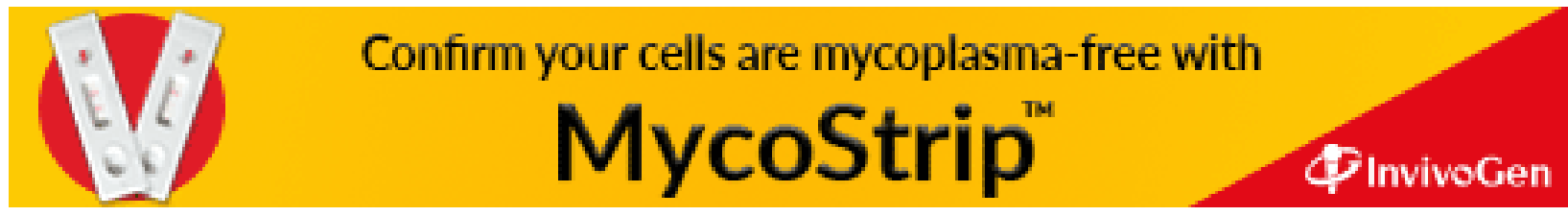

